\title{
"Girls are addicted to likes so they post semi-naked selfies": Peer mediation, normativity and the construction of identity online
}

\author{
Giovanna Mascheroni ${ }^{1}$, Jane Vincent ${ }^{2}$, Estefanía Jimenez ${ }^{3}$ \\ ${ }^{1}$ Department of Sociology, Università Cattolica of Milan, Italy \\ ${ }^{2}$ Department of Media and Communication, London School of Economics and Political Science, UK \\ ${ }^{3}$ Department of Media and Advertising, University of the Basque Country, Spain
}

\begin{abstract}
This paper examines how children aged 11-16 in three European countries (Italy, UK and Spain) develop and present their online identities, and their interactions with peers. It focuses on young people's engagement with the construction of an online identity on social media through pictures, and explores how peer-mediated conventions of self-presentation are appropriated, legitimated, or resisted in pre-teens' and teenagers' discourses. In doing so, we draw on Goffman's (1959) work on the presentation of self and "impression management" to frame our analysis. Mobile communication and social network sites serve an important role in the process of self-presentation and emancipation, providing "full-time" access to peers and peer culture. Our findings suggest that there are gender differences and the presence of sexual double standards in peer normative discourses. Girls are positioned as being more subjected to peer mediation and pressure. Boys blame girls for posing sexy in photos, and negatively sanction this behaviour as being aimed at increasing one's popularity online or as an indicator of "a certain type of girl." However, girls who post provocative photos chose to conform to a sexualised stereotype as a means of being socially accepted by peers. Moreover, they identify with the pressure to always look "perfect" in their online pictures. While cross-national variations do exist, this sexual double standard is observed in all three countries. These insights into current behaviours could be further developed to determine policy guidance for supporting young people as they learn to manage image laden social media.
\end{abstract}

Keywords: self-presentation, selfies, social network sites, young people, peer mediation

\section{Introduction}

In this paper, we explore teenagers' and pre-teens' discourses around the process of self-presentation and impression management online. Our aim is to understand how patterns of online identity - including gender and sexual identity - are socially constructed, reproduced, or resisted in the daily use of mobile internet technologies.

Constructing an autonomous identity is a fundamental task for adolescents and pre-adolescents. Rather than being an individual accomplishment, however, identity is better understood as a social and relational process that is embedded in peer cultures. Identities are constituted through interactions with others, by means of both identification and differentiation from the peer group (Buckingham, 2008; Corsaro \& Eder, 1990). 
Research has shown that mobile internet technologies and social networking sites have become fully incorporated in young people's everyday lives, potentially providing "full-time" access to peers (Bond, 2014; boyd, 2014; Livingstone, 2008, 2009; Mascheroni \& Ólafsson, 2014). As a consequence, social networking sites and mobile communications have expanded the range of identity spaces where teenagers and pre-teens creatively engage in their self-presentation. The literature on mobile communication and children has long recognised how the mobile phone is used to tie the group together and, at the same time, manage the fragile balance between identification and individuation in interpersonal relationships with peers (Caron \& Caronia, 2007; Green \& Haddon, 2009; Stald, 2008). Studies on young people's use of social networking sites similarly emphasised the strong influence of peers' cultures and normativity on patterns and practices of identity-making online (boyd, 2007, 2014; Livingstone, 2008).

This paper provides an analysis of new research examining how children aged 11-16 in three European countries develop and present their online identities through their use of photos and their interaction with peers. More specifically, it draws on qualitative data collected in 2013 and 2014 in three European countries - Italy, Spain, and the UK - as part of the EU Kids Online and the Net Children Go Mobile projects. Overall, a set of 24 focus groups and 48 individual interviews have been analysed in order to understand: 1) how young people engage in the construction of a (visual) online identity on social media platforms, 2) how peer-mediated codes and conventions of online self-presentation are appropriated, legitimated, or resisted in pre-teens' and teenagers' discourses, and 3 ) to what extent do codes and conventions of self-presentation vary based on gender.

\section{Social Media as Spaces of Identities}

Since the inception of internet studies, several authors who are concerned with the issue of online identity have drawn on Goffman's (1959) theory of self-presentation. Despite differing profoundly in terms of the identity spaces they offer and the forms and practices of self-presentation they afford, personal homepages (Papacharissi, 2002), blogs (Brake, 2012) and social networking sites have been framed as "stages" in the Goffmanian sense. Similarly, in the field of mobile communication studies, Goffman's (1959) work has been drawn upon to explain the way mobile phones are being used to mediate social interaction (Caron \& Caronia, 2007; Ling, 2008) and the presentation of the self (Stald, 2008; Vincent, 2011, 2012).

As it is well known, in his "dramaturgical" account of social interaction and its rituals, Goffman (1959) shows how, while in the presence of others, individuals engage in an ongoing, selective self-presentation aimed at controlling the definition of the situation and the impressions made on co-present actors. Selfpresentation, then, is about social rituals of "impression management" and involves learning how to deal with others' responses and maintain expressive control by putting on a "face."

For teens and pre-teens, online and mobile social networking has become an integral part of managing one's identity and social relations (boyd, 2007, 2014; Livingstone, 2008, 2009; Peter, Valkenburg, \& Fluckiger, 2009; Valkenburg, Schouten, \& Peter, 2005), and, inevitably, tensions arise out of the conflicting pressures in social media regarding what is considered appropriate and inappropriate to post and share about oneself and others. As in the offline contexts of interaction, information management and self-presentation are not simply an individual accomplishment, but rather a social process. Through creating and updating their profiles, teens and pre-teens conform to socially shared rules of selfpresentation, to social expectations regarding the size and nature of social connections, the kind and amount of personal information disclosed, and privacy settings. Two main identity patterns on social networking sites have been identified, corresponding to different ages. Younger children tend to perform an "an elaborate, highly stylized statement of identity as displayed" (Livingstone, 2009, p. 109), incorporating cultural tastes and lifestyle choices into the process of self-expression. Older teenagers, however, prefer a representation of identity "as connection" giving voice to the so-called relational self (Peter et al., 2009). Both patterns are socially constructed.

Social conventions and codes of self-presentation shared within peer cultures are also enabled and shaped by the design of the platform. In designing their profiles, teenagers are "constrained in two ways: first, by the norms and practices of their peer group and, second, by the affordances of the technological interface" (Livingstone, 2008, p. 400).

Indeed, two specific affordances of social media - "invisible audiences" and "collapsed contexts" - pose new challenges to the process of self-presentation and "impression management" online because they complicate the definition of the situation (boyd, 2014). The social context of interaction is defined as a "front" or a "back-stage" on the basis of the imagined audiences, and, often, on the presence of physical 
boundaries. Networked publics mean that unrelated audiences and disconnected social contexts can easily collapse, and the separation between "front" and "back" spaces becomes more problematic to manage. Additionally, boyd (2014) suggests that much of the teens' online behaviour seems whimsical and inappropriate to adults, but these behaviours are carried out in an effort to control their self-presentation and the social situation.

\section{Selfies, Visual (Re)Presentation and Peer Cultures}

Self-portraits and visual communication have been common uses of mobile phones since the commercialisation of camera phones (Lasén, 2005; Scifo, 2005). Indeed, mobile phone cameras are used more as prior to 2000 photographic practices required images to be separately developed and printed, which limited how young people could use images in their social relationships (Tinkler, 2008). New functionalities of smartphones, such as the front-facing camera, and the possibility to share content online have now turned "selfies" into a mainstream cultural practice. Teens and pre-teens have incorporated selfies in the process of exploring their identity and as a means of "presentation, representation, and embodiment" (Lasén, 2012). The study of selfies has also pointed to their being tools for selfimprovement and self-knowledge (Rettberg, 2014) as well as means of expressing resistant discourses (Bosch, 2011; Mazzarella, 2010).

However, the ease with which one can share self-portraits and images poses new challenges to the goal of "impression management." Keeping control of one's image and how one wants or does not want others to present him or herself online is an issue in children's discourses (Haddon \& Vincent, 2014). Moreover, visual self-presentation is highly gendered as it is about conforming to idealised patterns of femininity and masculinity. Prior research has already pointed to the normative character of patterns of self-portraits, focusing especially on the growing sexualisation of culture and society and the diffusion of hypersexualised feminine and masculine models (Attwood, 2009; Gill, 2007).

There is evidence that boys and girls do not passively reproduce the hyper-ritualised and hyper-sexualised models circulated by advertising and celebrity culture (Bosch, 2011; Ringrose \& Eriksson Barajas, 2011; Willem, Araüna, Crescenzi, \& Tortajada 2012). Nonetheless, gender imbalances and a "sexual double standard" exist, with boys and girls participating in gendered subcultures, and being subjected to different norms and notions of socially legitimate behaviour (Lyons, Giordano, Manning, \& Longmore, 2011). Girls are socialised towards a post-feminist model of feminine desirability - one which wants them sexually attractive and active - and are at the same time more subject to peers' moral judgements than boys, who are pushed to conform to an idealised masculinity centred on toughness and emotional disconnection (Lemish, 2015). The negotiation of gendered models dictated by popular culture is always contingent and embedded in social relationships (Lemish, 2015; Lyons et al., 2011)

In the next section, the methods used to obtain the data that forms the basis for our research enquiry are set out. The paper goes on to present the results of the interviews and focus groups that are pertinent to our analysis herein and discusses the themes identified in this introduction with particular emphasis on peer culture and mediation of visual self-presentation. Final thoughts for future research are presented in the conclusion.

\section{Methods}

During 2013 and 2014, we conducted two large qualitative research studies across Europe, as part of the EU Kids Online (Smahel \& Wright, 2014) and Net Children Go Mobile (Haddon \& Vincent, 2014) projects. The EU Kids Online study was aimed at investigating the meaning of online risks for children from the viewpoint of what children themselves define as problematic on the internet. Fieldwork was carried out in nine countries (i.e., Belgium, Czech Republic, Greece, Malta, Italy, Portugal, Romania, Spain, and the UK) from February to September 2013. The interviews and focus groups covered children's online activities, children's perceptions of online problematic situations, their own experiences of online risks, and coping strategies and preventive measures.

The Net Children Go Mobile study followed a similar research design. While this project was also ultimately interested in risks and safety of mobile internet technologies, the paucity of research on children and smartphones and children and tablets suggested a more thorough investigation of children's mobile media and mobile internet experiences. Accordingly, the interviews and focus groups addressed the following topics: the domestication of smartphones and tablets (i.e., perceptions, experiences, every day practices, favourite activities, changes associated with the new devices), problematic situations (i.e., perceptions, experiences, coping and prevention), and mediation of activities from parents and schools. Interviews and 
focus groups with children were conducted from January to September 2014 across nine countries (i.e., Belgium, Denmark, Germany, Ireland, Italy, Portugal, Romania, Spain and the UK).

In order to understand how young people engage in the process of self-presentation on social media, we focus on data collected in Italy, Spain and the UK as part of both projects, and from the age groups 11-13 and 14-16 year-olds. This decision is evidence-based. We selected the countries and the age-groups within which the issue of visual self-presentation on social networking sites and its gendered nature were most discussed, and presented more tensions between idealised patterns and actual performances of selfpresentations. Both research projects involved 4 focus groups (one with boys and one with girls for each age-group) and 8 individual interviews (4 per gender, with the same age distribution) in each country, amounting overall to a set of 24 focus groups $(N=107)$ and 50 individual interviews $(N=50)$. Participants were recruited from at least three different schools to allow for a more diverse sample.

In both projects, focus groups and interviews were transcribed in national languages and significant excerpts were also translated into English. The model of analysis set up in the EU Kids Online project was then replicated and adapted in the Net Children Go Mobile project. The analysis consisted of two steps. In the first level of coding (Rennie, Phillips, \& Quartaro, 1988), two researchers from each national team coded at least two transcripts and shared it with the coordinator, in order to ensure a validation of the coding process (Smahel \& Wright, 2014). This consisted in short descriptions of the material in English, that were then thematically analysed by a different team of researchers through a second level of coding based on the following areas: a) research area: problematic situation experience, problematic situation impact, problematic situation awareness, preventive measures, online activities, mediation, literacy, opportunities, researcher comments, off topic; b) Problematic situation: strangers, bullying and harassment, sex, unwanted content, commercial risks, technical problems, health and overuse; c) Platform: social networking sites (SNSs), email, pop-ups, websites, chat and message, video platforms, games and virtual worlds, online phone and video, school platforms, boards and forums, mobiles and tablets; d) Actors - who was involved: respondent, friend, peer, sibling, parents, teachers and school, media, other people; and e) Feelings: if any feelings were expressed. Drawing on this experience, the Net Children Go Mobile study (Haddon \& Vincent, 2014) adopted a similar coding manual, which included a separate code for devices (e.g., smartphones, mobile phones, tablets, other mobile devices, ebook reader, laptop, desktop computer, games console, ICTs) and platforms (e.g., Facebook, Twitter, Instagram, other SNS, Whatsapp, other instant messaging, games and virtual worlds, YouTube, websites, email, chat, apps, Google, pop-ups, eBay and Amazon, online phone, school platforms, online forum, location-tracking), as well as codes for the process of domestication of smartphones and tablets by children (e.g., ownership versus shared use, choice of the device/platform, motivations, cost, location of use, time).

In order to understand how visual-self presentation was discussed, the first-level codes were searched thematically by means of second-level codes (e.g. combining platform and problematic experience) and by keywords (e.g., photos, images, likes). It is notable that the word "selfie" was not used so prevalently by the children and young people during the period of our research (2013-2014). Instead they would talk about self-portraits or taking photos of themselves rather than taking a "selfie."

\section{Results}

The outcome of the two studies provides evidence from each of the three countries that girls and boys participate in the peer culture of the visual presentation of the self on SNS. This peer culture is gendered and involves issues of peer driven morality and sexualised identities. Most of the children in all countries (80\% - see Mascheroni \& Ólafsson, 2014) use a picture that clearly shows their face as their profile picture and, as we discuss later, it is not uncommon for this image to have been edited to convey an ideal impression of their self rather than reality.

The children and young people we interviewed discussed many aspects of their identity management on SNS, mostly unprompted by the interviewer. There is a general perception among the respondents that they are well informed and confident about matters of risk. Issues related to self-exposition and the disclosure of someone's image were often expressed assertively and with awareness of the ramification of the acts, such as reference to sexual offenders and what is wrong and what is right about what their peers do online. Their assertiveness extends to understanding the ramification of using an inappropriate pose or image on SNS. However, the respondents often vacillated between participating in the blaming and condemnation of overt sexuality and misrepresentation of the self on SNS whilst at the same time admitting to the presentation of their own self image in ways that could be construed as fake. 
These boys from the UK discussed a problem that occurred in their school in which they explored both participation in and condemnation of inappropriate actions:

Roland: Yes, someone in our year was sending an inappropriate picture around so a lot of the boys had it on their phones... and then the teachers found out, and, then the boy that asked for it and then the girl that sent it are now on the sex offenders' list.

Interviewer: Did she really send it around or did she send it to one boy?

Roland: She sent it to one person and then the boy told that he wouldn't send it to anyone because I think they both liked each other and then...

David: Now they don't.

Roland: Yes, now...

David: And what do you think so they're both on the list?

Roland: I don't really know because I wasn't really involved with it because I was in year seven, I didn't really, like, pay much interest to it.

Interviewer: Okay, so it was an older year when you were in year seven?

Roland: No, when we were in year seven it was just the more mature kids that knew about all that stuff.

Interviewer: Do you think the teachers kind of handled it well or do they know?

Theo: They handled it well.

Roland: Yes, they did.

Matthew: They just, they, like, I think they gave the right actions.

Jack: All the names that were heard were all called up; the headmaster came out and then

told everybody what's going to happen and the consequences.

Theo: And then it did kind of quieten down after, quite quickly after.

(UK, 14-16, boys, EU Kids Online)

This is not to say that these boys were correctly informed about these matters but they behaved as if they were. Furthermore, while they may be aware about online risks associated with the exchange of explicit images (sexting) they do not usually critically question the gender bias. Ringrose, Harvey, Gill, and Livingstone (2013) have shown the sexual double standards that can apply, such as in the willingness to pass on images of girls, thereby creating an exchange value among boys who at the same time are criticising and shaming the girls for posing in the first place. This blaming others, whilst participating in activities and then condemning actions, was typical of the boys and girls we interviewed individually and in focus groups. For example, when a girl decided to appear on SNSs in a certain way, to be seen in a sexy pose, it is assumed that she is aware of the consequences of her choice, which she has made in order to exhibit her social identity according to given models and roles. Although this may not necessarily always be the case, her decision infers she has accepted responsibility for the social identity she is choosing to project, especially when she knows it may be passed to others by people she may not know.

Maria: You already know that by sending a pic by Whatsapp or uploading it to a SNS, it's in everybody's hand, so you must be careful. It's not necessary to hear about that anymore... I am careful with the pics I upload. For instance, I don't even think about uploading an image of myself in my bra.

(Spain, 14-16, girl, Net Children Go Mobile)

Interviewer: What don't you like about sharing pictures of yourself?

Giuliana: It's all what you hear on TV and around.

Marina: That there might be weird people that you have never met, who see your picture, look for you, look for your personal information, things like that.

Giuliana: It is because...

Marina: When you are good looking.

Giuliana: When you create a profile on Facebook you are asked where you live, what school do you go to, and indeed I didn't tell my school. I said, "It's my own business," for this reason.

Martina: Or when there's a nice girl on Facebook, everyone is asking, "Where do you live? Let's meet" and things like that.

Marina: Or photos. My mum often asks me for my phone, in order to check my messages, because I often take selfies with her make up on... I post them, I mean those in which I am good looking. I soften the picture and upload them on Instagram.

(Italy, 12-13, girls, Net Children Go Mobile) 


\section{Gendered Peer Cultures and the Visual Presentation of the Self on SNS}

While both boys and girls engage in the visual presentation of their online selves, young people's discourses on identity management on SNS are polarised along the lines of gender differences, as a "we" versus "them" opposition. Girls are assumed to rely more on their visual self-presentation than boys, but this discourse is differently articulated, and suggests tensions between what is socially constructed as appropriate for a boy or a girl and what is actually enacted. The narrative is critical among boys, who distance themselves from the practice of photography or of selfies as typically feminine:

Valerio: While girls, they take selfies at home.

Matteo: In front of the mirror.

Valerio: As if they were celebrities.

(Italy, 12-13, boys, Net Children Go Mobile)

Jose: I don't post photos. I only have about a thousand or so visits, and that's not much! I've seen people who have 3,000 or more. And that is because they post a lot of photos, so their visits go up and up... It is obvious who posts photos and who doesn't! I have photos there, if I am tagged, and if not... I don't like posting photos actually!

(Spain, 14-16, boy, EU Kids Online)

Fabio: well, my camera is not working so... and on top of that, I am not the kind of person who takes self-portraits, I mean. I could take pictures with a friend, as a memory, but alone!

Luckily I see that most of my friends [behave like me]. Taking a self-portraits I think it is... useless!

Interviewer: So people are used to taking pictures and sharing them?

Fabio: On Facebook and stuff... A friend of mine the other day, that was because he had just dyed his hair blonde, so he took a self-portrait and posted it online. And this makes me laugh, because... even though nowadays...

(Italy, 16, boy, Net Children Go Mobile)

Girls, instead, discuss the liberating, empowering feeling associated with selecting and controlling their online appearance. However, further analysis shows how the liberating potential of self-presentation through selfies is actually constraining. Feminist scholars emphasised the binding nature of specific (neoliberal) aesthetic models of femininity to which young women "choose to conform" because their very selfconfidence is grounded in their beauty and appearance (Gill, 2003; Stuart \& Donaghue, 2012). Indeed, some girls explicitly link their social acceptance with the approval of their online self-presentation, thus reconfiguring the number of likes received to the pictures they share online as symbolic tokens of social inclusion. Girls post pictures consistent with conformist beauty standards to avoid being marginalised:

Christina: If you do not get likes it makes you feel no-one is interested in you. (UK, 13-14, girls, EU Kids Online)

Sara: Facebook has become a sort of ... second home! Yes, I mean, everything that happens in your daily lives is shared there, photos... Also, it is important to change the profile picture frequently because if you always keep the same you are no longer considered. (Italy, 15, girl, Net Children Go Mobile)

Simona: My stepsister is as old as me but she is ... a bit overweight, fatty, has very curly hair, so she does not receive many likes. So sometimes she feels upset, "it is not fair, you receive many likes" - many, my maximum is 40 - "you receive 40 likes and I get only 10." So if you really are a good friend, you edit the pictures to make her look more beautiful. She has never had many pictures in which she looks beautiful, but her face is not so bad. So I took a picture of her, we edited together, and I posted on Facebook - because I have more friends so it is more likely I get likes - and we got 25! (Italy, 13, girl, EU Kids Online)

This desire to have an identity and perceived image that is acceptable to others has been taken to extremes by some, especially girls. Two girls from the UK expressed concern about the impact of these social pressures such as to have a visible space between their inner thighs (thigh gap) and perfect features and how girls would diet, even becoming anorexic in their quest for a perfect body. 
Bea: One of the main girls who has it was hospitalised by it and stuff. She was obsessed with her thigh gap.

Elsa: Oh yes, thigh gaps, have you heard about them?

(UK, 14-16, girls, Net Children Go Mobile)

While girls perform a selective self-presentation, by carefully choosing the pictures in which they are good-looking, they also point to the fragile balance between managing the impression of others and authenticity. As a consequence, the use of photo-editing apps for smartphones is legitimised under two different frameworks: funny make over or the "girl next door" frame. By contrast, the use of photo-editing apps to produce a "perfect" image is sanctioned as fake and "ridiculous."

Bea: I think it affects quite a lot of people but not on... I don't see it on Twitter as much, but on Instagram because people, you see them at school one day and they, I don't know, don't have very big eyebrows and they don't have like perfect skin. Then on Instagram that night they'll have like huge big arched eyebrows and perfect skin, perfect contours and really big cheekbones and then people who don't know them follow them.

Elsa: There's this girl in Year Nine she's like 13, 14, anyway, on these SNS, oh, my gosh, I'll have to show you after, she looks about 30 and she's so provocative with her photos and boobs out, bums out, belly out everything out, and all these boys who she doesn't even know will be coming to her, oh, you're so pretty. If you see her in real life she's like... She's got straight hair. She's not ugly, but she's just a normal looking person you wouldn't see her on the street and go you're so pretty but it's, so it's like and it's just so different and it's just like a, yes, it is a fake identity.

(UK, 14-16, girls, Net Children Go Mobile)

Simona: My (girl) friends and I look at the pictures and select a few. Because we really take a lot of photos, then we select a few. There are also these new apps for phones that let you edit pictures... so we enjoy taking pictures, editing them and seeing the final result. But there are people who - because these apps let you conceal blemishes, and there are people who overuse it, they boast china-type skin, that is ridiculous, exaggerated. (Italy, 13, girl, EU Kids Online)

For the construction of the sexual identity it is not only important that the appearance is re-created by the pictures, but also that the context involved is shown - in other words the clearly sexualized places the girls have visited. This is not at all difficult to decode:

Paula: Some people keep their profiles on SNS open so that they can show off. For instance, I know some girls who upload some pics of a disco so that everybody can see they have been there.

Interviewer: To show off?

Paula: That's right. In order to get attention. The cases I know are girls. Maybe they go to the beach and take some pics. They label the boys they like so as to tell them, "Look, how I am?" Or maybe they take pictures of themselves in the disco, drunk, to be cool like, "Look, I am at the disco, drunk, I danced on the bar." For people to know they have been there.

(Spain, 14-16, girl, EU Kids Online)

However, children's discourses suggest a more complicated picture and there are incongruities with regard to how they see others versus how they view themselves. Furthermore, despite the normative pattern being that of girls being more keen on their visual self-presentation than boys, some boys are also sensitive to the normative selective self-presentation and conform to ideal standards by selecting only "good pictures:"

Valerio: There's an app for Facebook called Webcamtoy... it uses the front camera to take pictures with different effects.

Interviewer: And then, do you share these pictures?

Valerio: Sometimes, except when I am not good looking.

Giulio: I don't, I feel embarrassed.

(Italy, 12-13, boys, Net Children Go Mobile)

It is not only pictures but also the words they use to talk about themselves that can be a distortion of the truth. Bea describes a Twitter account of a boy she knows at school in which he portrays a completely different image of himself from the reality she sees in person:

Bea: There's this boy, I won't name him, but he's so shy and awkward and just doesn't say anything in real life. Then on Twitter he's like, he just beefs himself up so much. And then 
when I met him I was asking about all the things he tweets about and he was just, he doesn't sound like he would, I don't know, and I don't like how some people they just, it's just it's a trick it's like bad, it influences you to think something totally wrong.

(UK, 14-16, girls, Net Children Go Mobile)

By contrast, girls can also critically engage with peer culture and its norms, as when they express the constraining nature of standardised self-presentation and try and find alternative communication platforms to share their visual self-representation with intimate friends. For example, Snapchat is remediated as an empowering channel that emancipates girls from the tyranny of beauty and lets them engage in playful communication by sharing pictures in which their appearance is neither perfect nor sexually desirable.

Gaia: Yes, it is an app that doesn't save photos, so I can take even ugly pictures, because they are useless, than I write a comment under the photo, I can add colours, and whatever I want and send it. And my friends can see it for 6 seconds, then it expires, and sometimes we have conversations through these kinds of messages. Nothing is saved, so you don't feel like, "OMG, this picture is not good enough."

(Italy, 14-16, girls, Net Children Go Mobile)

\section{Peer-Driven Morality and Sexualised Identities}

The normative pattern for feminine visual identity is increasingly sexualised. While some girls choose to conform to it, other girls and especially boys condemn the sexualised self-presentation as inappropriate and unacceptable. Posing sexy is seen as deliberately transgressing parental and peer-driven morality regarding what being "a good girl" involves. Discourses in which boys blame girls for sharing provocative pictures develop around two main themes. The first connects sexy pictures with the search for popularity and social inclusion. "Posing sexy" is framed by boys as an inappropriate, unsuccessful, and problematic means of gaining social acceptance by conforming to a pattern of adult femininity:

Valerio: And now there are girls, not many boys, but girls who...

Matteo: Who do strange things.

Valerio: Yeah, with dresses or, don't know, with off shoulder tops, just to get more likes.

Matteo: Yeah, or all covered with make up.

Valerio: Indeed, tons of make up.

Matteo: Loads of mascara.

(Italy, 12-13, boys, Net Children Go Mobile)

As anticipated, the number of likes they receive on their profiles is understood as an indicator of their inclusion in the peer group. As Michele, a 15 year-old Italian boy said: "It is more a girl thing to want many 'likes,' and many friends in order to be accepted" (Italy, 14-15, boys, Net Children Go Mobile). According to boys, girls need social acceptance so much that they become "addicted" to likes:

Massimo: Mmm, then, there are many girls who are addicted to likes, so in order to get more likes to their pictures, they post selfies in which they are semi-... not semi-naked but...

Michele: Girls like it. They "like" each other photos.

Massimo: Then they write, "You're my love..."

Michele: Yes, because then all of them write, "You are so beautiful!" That kind of stuff... they play these tricks, and even if the pictures are objectively bad, they all say, "You are awesome" and the other "You more than me."

Massimo: Then they might not even care about each other.

Michele: Yeah, exactly

Massimo: Or they go to their friend, "Look how ugly she is!"

(Italy, 14-15, boys, Net Children Go Mobile)

In condemning girls, boys reinforce gender stereotypes. They claim that girls who post

provocative pictures are usually not beautiful enough, nor are they conforming to cultural

codes of femininity, and that they just want to be accepted by the peer group. As such, they are ridiculed and stigmatised:

Francesco: There's something crazy, I mean, especially girls, since they are "affected." I mean, every time they post a picture, if they don't get the right amount of likes... they are addicted! So there's this group, don't know if you have seen it, "the most popular group on earth." Luca: Yes, I quit it.

Francesco: Yes, so did I, too many notifications. And it is mostly girls who post provocative pictures, despite being ugly, and they ask "Like my picture and I'll tell you how beautiful you 
However, there is evidence that, in managing their self-presentation on the internet, both girls and boys tend to eroticise their performance, modelling them on those they have come across in advertising throughout their life (Tortajada, Araüna, \& Martínez, 2013). In the following example from Spain, two boys, Adrián and Jorge, discuss the "advertising logic" based on the appeal of the exhibition of sexual parts of the body. This logic of sexualised self-presentation clearly operates according to a powerful sexual double standard. On the one hand, self portraits are asked for, offered, and shared as sexual lures, so it is assumed that they must reflect an attractive feminine beauty standard. On the other hand, this sexualised pattern contrasts with the equally normative model of respectable femininity, as Paula and Candice later explain:

Adrián: The girls who show their own photos and they may show their breasts on Twitter, or any other part of their body. And they say everyday: "Hello, my boys." And they upload a photo of their breasts. They don't mind as long as they get visits or followers.

Interviewer: That is, they are looking for followers, and that is why they show off part of their body?

Jorge: That's it! And the more followers you have, then... if then you want to do something, well... to see pussy... you can go on there.

(Spain, 14-16, boys, EU Kids Online)

Paula: When the picture is of a boy without a T-shirt or in his underwear, nothing is said, or "you are the boss"... but not if there is a girl. You can be insulted; they call you anything, trampy. Whore. If a pic of me would circulate I would make sure that everybody deleted it, in front

(Spain, 14-16, girl, EU Kids Online)

Candice: Yes, it does happen. Girls putting make-up on, sometimes girls don't really wear a lot of clothes, so they get a lot of friends' requests. That's when you see girls with 1,000 friends on

Interviewer: You can work out how they've come about. Candice: Boys, they take off their tops. If they've got a six-pack, they can show it and post it on Facebook.

Interviewer: Boys and girls are equally likely to do this type of thing? Candice: Yes, more boys than girls.

(UK, 11-13, girl, EU Kids Online)

Whilst girls are perceived as struggling for social acceptance, their sexy self-presentation is blamed as an indicator of their being "that kind of girl" or "a slut." This is the second issue raised by boys:

Fabio: I don't know if they exchange photos. Maybe that they take photos a bit undressed to put on Facebook, yes, that is true. And it is for this reason that... I am ok with everything, we are men and all that, but you are not a good girl. I mean... you are an easy girl. You don't even know her. You are looking for a photo of her, because you have never met her before, and what do you see for the first time? Maybe a picture of her with revealing shorts or low-necked tops. And so things change, you see that person from a different perspective.

(Italy, 16, boy, Net Children Go Mobile)

Under these premises, girls who post provocative pictures "deserve" the negative consequences such as being bullied or being groomed by strangers:

Fabio: A girl posts a photo and afterwards everybody starts insulting her, this could be a way of bullying... I think that if someone does certain things, I mean, if you post certain photos you should expect it. Then I am aware it happened... it is mean, for tragedies occurred due to offences on Facebook, they also showed it on TV, on the news. Parents must not pretend they are not aware, because at the end, it is normal to take pictures and things, but if you feel it is degenerate you should stop it.

(Italy, 16, boy, Net Children Go Mobile)

As we have already seen, girls are ambivalent to how they frame the normative pattern of sexy femininity. Most girls, especially younger ones, adhere to the dominant discourse of blaming girls who post provocative pictures, and distance themselves from the practice and its meaning. For example, Stefania, a 13 year-old Italian, says her parents never wanted to check 
her pictures, as "I have always been a kind of, I mean, a responsible girl" (Italy, 13, girl, Net Children Go Mobile). And Paula, from Spain, agrees that sexually provocative pictures are exchanged in order to gain more popularity:

Interviewer: You appear in your bikini so that people know you have been at the beach?

Paula: Or so people pay you more attention! There are some people, girls I know, who upload their photos to catch the attention of guys. I don't like it. Most girls do it, or I have heard they do it. They have posted photos so you pay more attention to them, or their boyfriends like it. Interviewer: Because the boys have asked for it or...?

Paula: No, it's because they want to show themselves. It's a way to flirt, more or less, to show themselves.

(Spain, 14-16, girl, EU Kids Online)

However, teenage girls recognise that the unexpected negative consequences of sharing revealing pictures may be attributed to a lack of social media literacy (Livingstone, 2014) or to boys' misbehaviour rather than being caused by the girl's own questionable and immoral conduct, as in the two following examples:

Micol: Many people ignore this, so they post semi-naked pictures, things like that.

Ilaria: That they are permanent.

Micol: Yes, you may delete it after a couple of days, but it is there, you don't know where but it is there...

(Italy, 14-16, girls, EU Kids Online)

Giorgia: On Facebook I heard about a girl, I don't know if she is still there or she killed herself for this, that exchanged a photo with her boyfriend, in which she was undressed, and her boyfriend shared it publicly on Facebook. And they started insulting her. They said she was a slut and things like that. But she meant to send the photo only to her boyfriend.

(Italy, 16, girl, Net Children Go Mobile)

\section{Discussion and Conclusion}

Our findings reflect that in the three countries there are similar issues regarding self-presentation and online impression management. Clear gender differences in the codes and conventions of selfpresentation, and the presence of sexual double standards in peer normative discourses emerged. However, the analysis also showed the presence of subtle tensions between the discourses, reflecting idealised models of femininity and masculinity, and the practices in which discourses are embodied and performed.

While photography and self-portraits are generally assumed as being a feminine domain, the findings reveal how central photos are for both girls and boys in the process of presenting oneself to others on SNS. Visual self-presentation is clearly aimed at managing the impressions made on others and gaining acceptance by the peer group. Indeed, conformity to beauty standards and peer conventions is rewarded with peer validation and social legitimation as expressed by the number of likes, which are then equated to a marker of one's popularity. As a consequence, pictures that conform to a sexualised model of feminine or masculine beauty are understood as attractive in order to get attention.

However, as anticipated, both the codes of self-presentation that closely resemble the visual codes of advertising, and SNS are gendered. As Ringrose and Eriksson Barajas (2011) showed SNS are highly gendered identity spaces, providing risky opportunities to the process of identity construction. As a consequence, boys and girls tend to eroticize their self-presentation with similar perseverance but underlying different features, as noted by Willem et al. (2012) and Tortajada et al. (2013).

In making sense of the gendered norms regarding the use of photos in the process of "impression management" on SNS, boys and girls mobilise a sexual double standard. This finding is consistent with the most recent literature on sexting (Ringrose et al., 2013; Lippman \& Campbell, 2014). According to this normative framework, girls are positioned as being more subjected to both peer mediation and the pressure of an aesthetic model of adult femininity. Boys blame girls for posing sexy in their profile pictures and in the photos they decide to share with others online, and boys negatively sanction this behaviour as being aimed at increasing one's popularity online or as an indicator of "a certain type of girl." By contrast, girls who post provocative photos chose to conform to a sexualised stereotype as a means of 
being socially accepted by both their male and female peers. Moreover, they identify with the pressure to always look "perfect" in their online pictures.

Nonetheless, moral discourses are not passively appropriated, and boys and girls of different ages position themselves differently vis-à-vis the increasing sexualisation of culture. Pre-teens have shown quite aloof behaviour regarding sexual issues, sometimes trying to deny their interest or expressing disgust or rejection when asked about it or when explaining their classmates' not-so-reluctant attitude. By contrast, the constant presence of sexualised representations and their influence has become unavoidable for teenagers. While boys tend to adhere to a peer-driven moral discourse on sexy pictures, girls reflexively engage with the double pressure to conform to contrasting expectations and moral standards - being sexually attractive versus being "a good girl." Various criteria coexist based on the advisability of the pictures which girls decide to share. They are mostly based on self-control, and appropriateness to peerdriven morality, although some of them mention their parents having accounts on Instagram, which actually helps them evaluate to what extent is it convenient or not to upload their selfies.

To conclude, what normative discourses reveal is the shift from "what a young girl shouldn't do" to "how a cautious girl shouldn't appear." This highlights again the significance of "impression management," and its nature as a social process (boyd, 2014). In selecting how to present themselves online through photos, pre-teens and teenagers are actually engaging in the definition of what is socially acceptable, what gender and sexual identities are considered appropriate and legitimated, and what, by contrast, are less desirable, contested and stigmatised.

The present research has some limitations; the small number of respondents provided fewer examples of sexual double standards than might be obtained from a representative sample of a broader range of young people's identity issues and the associated tensions. We believe future studies focused primarily on visual self-presentation could shed more light on the norms and the gendered power imbalances that regulate the practice of sexting, as well as to explore whether some young people have greater freedoms to explore their self presentation than others, especially those who do not fit the peer norm for 'being good-looking' or who are perhaps exploring issues of gender or homosexuality. This additional knowledge could further inform awareness raising initiatives aimed at promoting responsible uses of the internet and respectful interactions among boys and girls within the age group we have explored in this paper.

\section{References}

Attwood, F. (2009). Mainstreaming sex: The sexualisation of Western culture. London: Taurus.

Bond, E. (2014). Childhood, mobile technologies and everyday experiences. Basingstoke: Palgrave MacMillan.

Bosch, T. (2011): Young women and 'technologies of the self': Social networking and sexualities. Agenda, 25(4), 75-86.

boyd, d. (2007). Why youth (heart) social network sites: The role of networked publics in teenage social life. In D. Buckingham (Ed.), Youth, Identity and Digital Media (pp. 119-142). Cambridge: MIT Press.

boyd, d. (2014). It's Complicated: The social lives of networked teens. Yale University Press.

Brake, D. R. (2012). Who do they think they're talking to? Framings of the audience by social media users. International Journal of Communication, 6(21). Retrieved from:

http://ijoc.org/index.php/ijoc/article/view/932

Buckingham, D. (2008). Introducing identity. In D. Buckingham (Ed.), Youth, Identity and Digital Media (pp. 1-24). Cambridge: MIT Press.

Caron, A., \& Caronia, L. (2007). Moving cultures. Montreal: McGill-Queen's University Press.

Corsaro, W. A., \& Eder, D. (1990). Children's peer cultures. Annual Review of Sociology, 16, 197-220.

http://dx.doi.org/10.1146/annurev.so.16.080190.001213

Gill, R. (2003). From sexual objectification to sexual subjectification: The resexualisation of women's

bodies in the media. Feminist media studies, 3(1), 100-106. 
Gill, R. (2007). Gender and the media. Cambridge: Polity Press.

Goffman, E. (1959). The presentation of self in everyday life. Middlesex: Penguin.

Green, N., \& Haddon, L. (2009). Mobile communications: An introduction to new media. Oxford: Berg.

Haddon, L., \& Vincent, J. (2014). European children and their carers' understanding of use, risks and safety issues relating to convergent mobile media. Milano: Educatt. Retrieved from: www.netchildrengomobile.eu/wp-content/uploads/2013/07/NCGM_QualitativeReport_D4.pdf

Lasén, A. (2005). Understanding mobile phone users and usage. Newbury: Vodafone Group R\&D.

Retrieved from: http://eprints.ucm.es/6477/

Lasén, A. (2012). Autofotos. subjetividades y medios sociales [Selfies: Subjectivities and social media]. In García-Canclini, N., \& Cruces, F. (Eds.), Jóvenes, culturas urbanas y redes digitales. Prácticas emergentes en las artes, el campo editorial y la música [Young people, urban cultures and digital networks. Emerging practices in arts, editorial field and music] (pp. 243- 262). Madrid: Ariel.

Lemish, D. (2015). Children and media: A global perspective. Malden: Wiley.

Ling, R. (2008). New tech, new ties. Cambridge, MA: MIT Press.

Lippman, J. R., \& Campbell, S. W. (2014). Damned if you do, damned if you don't... if you're a girl: Relational and normative contexts of adolescent sexting in the united states. Journal of Children and Media, 8, 371-386. http://dx.doi.org/10.1080/17482798.2014.923009

Livingstone, S. (2008). Taking risky opportunities in youthful content creation: Teenagers' use of social networking sites for intimacy, privacy and self-expression. New Media \& Society, 10, 393-411.

http://dx.doi.org/10.1177/1461444808089415

Livingstone, S. (2009). Children and the Internet. Cambridge: Polity.

Livingstone, S. (2014). Developing social media literacy: How children learn to interpret risky opportunities on social network sites. Communications, 39, 283-303. http://dx.doi.org/10.1515/commun2014-0113

Lyons, H., Giordano, P. C., Manning, W. D., \& Longmore, M. A. (2011). Identity, peer relationships, and adolescent girls' sexual behavior: An exploration of the contemporary double standard. Journal of sex research, 48, 437-449. http://dx.doi.org/10.1080/00224499.2010.506679

Mascheroni, G., \& Ólafsson, K. (2014). Net Children Go Mobile: Risks and opportunities. Milan: Educatt. Retrieved from: www.netchildrengomobile.eu/reports

Mazzarella, S. R. (Ed.). (2010). Girl wide web 2.0: Revisiting girls, the Internet, and the negotiation of identity. New York: Peter Lang.

Papacharissi, Z. (2002). The presentation of self in virtual life: Characteristics of personal home pages. Journalism \& Mass Communication Quarterly, 79, 643-660.

http://dx.doi.org/10.1177/107769900207900307

Peter, J., Valkenburg, P. M., \& Fluckiger, C. (2009). Adolescents and social network sites: Identity, friendship and privacy'. In S. Livingstone \& L. Haddon (Eds.), Kids online. Opportunities and risks for children (pp. 83-94). Bristol: Policy Press.

Rennie, D. L., Phillips, J. R., \& Quartaro, G. K. (1988). Grounded theory: A promising approach to conceptualisation in psychology Canadian Psychology, 29, 139-150. http://dx.doi.org/10.1037/h0079765

Rettberg, J. W. (2014). Seeing ourselves through technology: How we use selfies, blogs and wearable devices to see and shape ourselves. Palgrave Macmillan. 
Ringrose, J., \& Eriksson Barajas, K. (2011). Gendered risks and opportunities? Exploring teen girls' digital sexual identity in postfeminist media contexts. International Journal of Media and Cultural Politics, 7, 121138. http://dx.doi.org/10.1386/macp.7.2.121_1

Ringrose, J., Harvey, L., Gill, R., \& Livingstone, S. (2013). Teen girls, sexual double standards and 'sexting': Gendered value in digital image exchange. Feminist Theory, 14, 305-323. http://dx.doi.org/10.1177/1464700113499853

Scifo, B. (2005). The domestication of camera-phone and MMS communication. Early experiences of young Italians. In K. Nyìri (Ed.), The global and the local in mobile communication (pp. 363-373). Wien: Passagen Verlag.

Smahel, D., \& Wright, M. (2014). Meaning of online problematic situation for children. Results of qualitative cross-cultural investigation in nine European countries. London: EU Kids Online. Retrieved from:

http://eprints.Ise.ac.uk/56972/1/EU_Kids_Online_Report_Online_Problematic_Situations_for_Children_Ju ne2014.pdf

Stald, G. (2008). Mobile identity: Youth, identity, and mobile communication media. In D. Buckingham (Ed.), Youth, identity and digital media (pp. 143-164). Cambridge: MIT Press.

Stuart, A., \& Donaghue, N. (2012). Choosing to conform: The discursive complexities of choice in relation to Feminine beauty practices. Feminism \& Psychology, 22(1), 98-122. http://dx.doi.org/

$10.1177 / 0959353511424362$

Tinkler, P. (2008) A fragmented picture: Reflections on the photographic practices of young people. Visual Studies, 23, 255-266. http://dx.doi.org/10.1080/14725860802489916

Tortajada I., Araüna N., \& Martínez I. J. (2013). Advertising stereotypes and gender representation in social networking sites. Comunicar, 41, 177-186. http://dx.doi.org/10.3916/C41-2013-17

Valkenburg, P., Schouten, A., \& Peter, J. (2005). Adolescents' identity experiments on the internet. New Media and Society, 7, 383-402. http://dx.doi.org/10.1177/1461444805052282

Vincent, J. (2011). Emotion and the mobile phone. In H. Greif, L. Hjorth A. Lasén, \& C. Lobet-Maris (Eds.), Cultures of participation: Media practices, politics and literacy (pp. 95-109). Frankfurt am Main: Peter Lang Verlag.

Vincent, J. (2012). Mediating emotions via visual communications: An exploration of the visual presentation of self via mobile phones. In A. Benedek \& K. Nyíri (Eds.), The iconic turn in education (pp. 85-96). Berlin: Peter Lang Verlag.

Willem, C., Araüna, N., Crescenzi, L., \& Tortajada, I. (2012). Girls on Fotolog: Reproduction of gender stereotypes or identity play? Interactions: Studies in Communication \& Culture, 2, 225-242.

http://dx.doi.org/10.1386/iscc.2.3.225_1

\section{Correspondence to:}

Giovanna Mascheroni

Department of Sociology

Università Cattolica del Sacro Cuore

Largo Gemelli 1

20123 Milano

Italy

Email: giovanna.mascheroni(at)unicatt.it 


\begin{abstract}
About authors
Giovanna Mascheroni, PhD, is a Lecturer in Sociology of Communication and Culture in the Department of Sociology at Università Cattolica of Milan and a Visiting Fellow in the Department of Media and Communications at the London School of Economics and Political Science. She was the coordinator of the Net Children Go Mobile project and has been the national contact of the EU Kids Online network since 2007. She is also part of the research project, WebPolEU: Comparing Social Media and Political Participation across EU (http://www.webpoleu.net/).
\end{abstract}
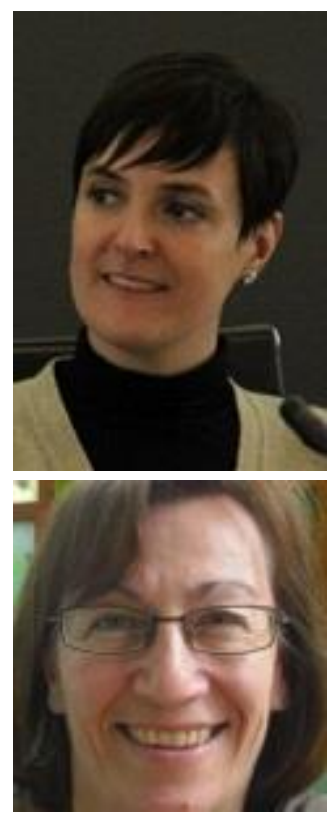

Jane Vincent, PhD, is a Visiting Fellow at the London School of Economics and Political Science. She participated in the Net Children Go Mobile and EU Kids Online projects for the UK and has led studies on children and mobile phones for the University of Surrey. Her research interests focus on information communication technology user behaviours and emotions and their usage of mobile phones.

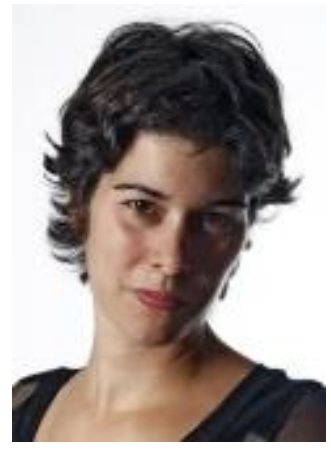

Estefanía Jimenez, PhD, is a Lecturer in Media Studies at the School of Social Sciences and Communication of the University of the Basque Country. She has been a member of the EU Kids Online network since 2012 and she has also participated in the Net Children Go Mobile project as the Spanish representative. She works on Media Literacy, audience research, and usage of SNS. 